\title{
To Detect and Reject, Parallel Roles for Taste and Immunity
}

\author{
Jason R. Goodman ${ }^{1} \cdot$ Robin Dando ${ }^{1}$ \\ Accepted: 23 March 2021 / Published online: 22 April 2021 \\ (C) The Author(s), under exclusive licence to Springer Science+Business Media, LLC, part of Springer Nature 2021
}

\begin{abstract}
Purpose of Review From single cells to entire organisms, biological entities are in constant communication with their surroundings, deciding what to 'allow' in, and what to reject. In very different ways, the immune and taste systems both fulfill this function, with growing evidence suggesting a relationship between the two, through shared signaling pathways, receptors, and feedback loops. The purpose of this review was to explore recent reports on taste and immunity in model animals and in humans to explore our understanding of the interplay between these systems.

Recent Findings Acute infections in the upper airway, as with SARS-CoV-2, are associated with a proinflammatory state, and blunted taste perception. Further, recent findings highlight taste receptors working as immune sentinels throughout the body. Work in humans and mice also points to inflammation from obesity impacting taste, altering taste bud abundance and composition.

Summary There is accumulating evidence that taste cells, and particularly their receptors, play a role in airway and gut immunity, responsive to invading organisms. Inflammation itself may further act on taste buds and other taste receptor expressing cells throughout the body as a form of homeostatic control.
\end{abstract}

Keywords Taste $\cdot$ Inflammation $\cdot$ Immunity $\cdot$ Obesity

\section{Introduction}

Taste is fundamentally linked to quality of life, and is vital in determining food choice. However, as well as to assay the appeal of foods with appetitive characteristics, the taste system chemically interrogates the food we eat, serving as a gatekeeper, protecting against the ingestion of aversive, unpalatable items that may cause harm if taken into the body. The immune system serves an analogous function, detecting things that are harmful, or that bear the molecular signals of those that have been harmful in the past, acutely activating against systemic insult as a first line of defense. In the time necessary for an adaptive immune response to generate, a pathogen may have grown to a problematic degree within the host, and therefore the innate immune response gives an "always on" protection to the body from novel

This article is part of the Topical Collection on Nutrition and the Brain

Robin Dando

robin.dando@cornell.edu

1 Department of Food Science, Cornell University, Ithaca, NY 14853, USA pathogens it may be initially naive to. The innate immune response utilizes an array of cells, signaling factors and proteins to isolate, destroy and recycle potential pathogens before they can reproduce to the point where they may become harmful to the host. Without an index of specific pathogens to identify, the innate immune response instead relies on detecting common molecules which are absent in the host, but which are often signs of a pathogenic entity, the classical example being Lipopolysaccharides, molecules commonly found in the external membranes of Gram-negative bacteria. Upon detection, the innate immune system responds to neutralize a perceived threat with both phagocytosis, whereby a potential intruder is engulfed and ingested, and with inflammation.

As the basic roles of immunity and taste share some overlap in function, it is unsurprising then that recent evidence has begun to suggest that these systems may interact, and further may influence one another. Most visibly in the past year during the Covid-19 pandemic, infection with the novel coronavirus was strongly and publicly associated with anosmia, a loss of smell [1], in a manner that may correlate with an activated inflammatory response [2], as well as with ageusia, a loss of taste, and further loss of oral perception of irritants $[3 \bullet \bullet$. Taste cells and their canonical signaling cascades are 
commonly implicated in auto and hyperimmune diseases. Many genes associated with the innate immune response are over-expressed in taste cells, particularly in those isolated from taste cells bearing the molecular signals of type II taste cells [4], the cells responsible for sweet, umami and bitter taste detection. In the taste buds of humans, inflammation and innate immune-associated genes are readily up-regulated in obese compared to lean individuals [5•0]. Being overweight or obese (a condition affecting over $65 \%$ of adults in the USA), is associated with chronic low-grade inflammation, and is linked to alterations in taste or food intake patterns, usually promoting overconsumption, and correlating with a loss of taste function. Taken together, evidence points toward a feedback relationship between the immune and taste systems that may have implications for how the body functions to keep us safe from pathogens, and for our metabolic health in general.

In this review, we will concentrate on recent findings (primarily those from the past 5 years) regarding immunity, inflammation, and taste to provide a snapshot of our current understanding of how these systems interact, and highlight further interesting questions that future work may explore.

\section{Search strategy and selection criteria}

PubMed and Google Scholar were used to search for primary research articles, over the previous 5 full years from 2016 to 2020 , with a small number of important articles from earlier than this also included for context. Search terms included "taste", "inflammation", "immunity", "autoimmune", "obesity", "cancer", and various combinations thereof. Summaries and reviews were largely excluded to concentrate on most recent primary literature from the lab or clinic. Recent studies in non-human animals are highlighted in Table 1, with studies in human subjects in Table 2 .

\section{Molecular markers of inflammation}

Inflammation as a term encompasses the activation of the immune system toward an insult. This is characterized on the macroscale by an increase in blood flow leading to redness, swelling, and an increase in temperature, along with pain and potentially a temporary loss of function [18], and on the cellular scale by the recruitment of neutrophils, macrophages, and monocytes, as well as proinflammatory cytokines like Tumor Necrosis Factor alpha (TNF $\alpha)$ [19] and Interluekin-6 (IL-6) [20], other markers of inflammation like C-Reactive Protein (CRP) [21] and chemokines like Monocyte Chemoattractant Protein-1 (MCP-1) [20]. This contrasts with the more specific actions of the adaptive immune system acting post antigen presentation via $\mathrm{B}$ or $\mathrm{T}$ cells, to an already familiar threat.

While, in many cases, these acute phase effectors resolve after insult, a chronic low-grade inflammation, or metaflammation [22], has been observed in overnutrition and obesity [23]. Overfeeding also leads to hyperinsulemia and hyperleptinemia [24], as resistance to the effects of insulin or leptin necessitates their overproduction. Evidence points to proinflammatory cytokines directly acting on the insulin [25] receptor, and leptin receptors (among other mechanisms of leptin resistance $[26,27])$ to affect this change. Interestingly, many proinflammatory signaling factors associated with inflammation also have their cogent receptors expressed in taste buds [28-30], proffering a potential mechanism for their upor down-regulation being associated with a modulation of taste function. TNF $\alpha$ knock out (KO) mice are less sensitive to bitter stimuli than wild type animals [31], and exogenous $\mathrm{TNF} \alpha$ seems to blunt sodium taste by inhibiting sodium flux in taste buds [32].

\section{Bacterial infection}

Lipopolysaccharide (LPS), an inducer of acute inflammation of bacterial origin, has been utilized by multiple groups to model the influence of systemic inflammation on the taste system. Exogenous LPS resulted in a reduction in the proliferative capacity of taste buds [33] which are constantly renewing in nature, and altered licking response to $\mathrm{NaCl}$ in mice $[32,34]$, supported by reduced activity in the chorda tympani nerve which takes taste information from the anterior tongue to the brain, in response to various taste stimuli [34••]. Serum-LPS is also elevated in mice experiencing systemic inflammation through consuming a high-fat diet (HFD) $[11 \bullet \cdot$. In one intriguing study, the bitter tastant (of recent infamy), chloroquine, was found to exhibit protective effects on pre-term birth in mice, when induced through LPS injections (inflammation is a key risk factor for pre-term labor) [35]. Protective effects were much weaker in animals lacking the G-protein alpha-subunit Gustducin (originally thought to be taste-specific, although now associated with many chemosensory cells throughout the body), suggesting that protective effects were mediated in a manner analogous to taste signaling, via bitter receptors which were found expressed in myometrial cells. Interestingly, the primary receptor for LPS, TLR4 [30], is also expressed in taste buds, whereby taste preference is altered in mice deficient in TLR4, with KO mice displaying a reduced preference for sugars, lipids, and umami [36], further suggesting that an innate inflammatory response may alter taste function. Taken together with earlier work, this suggests a dual function for the LPS/TLR4 pathway; (1) as a sensor of inflammation which can damage taste buds, and (2) 


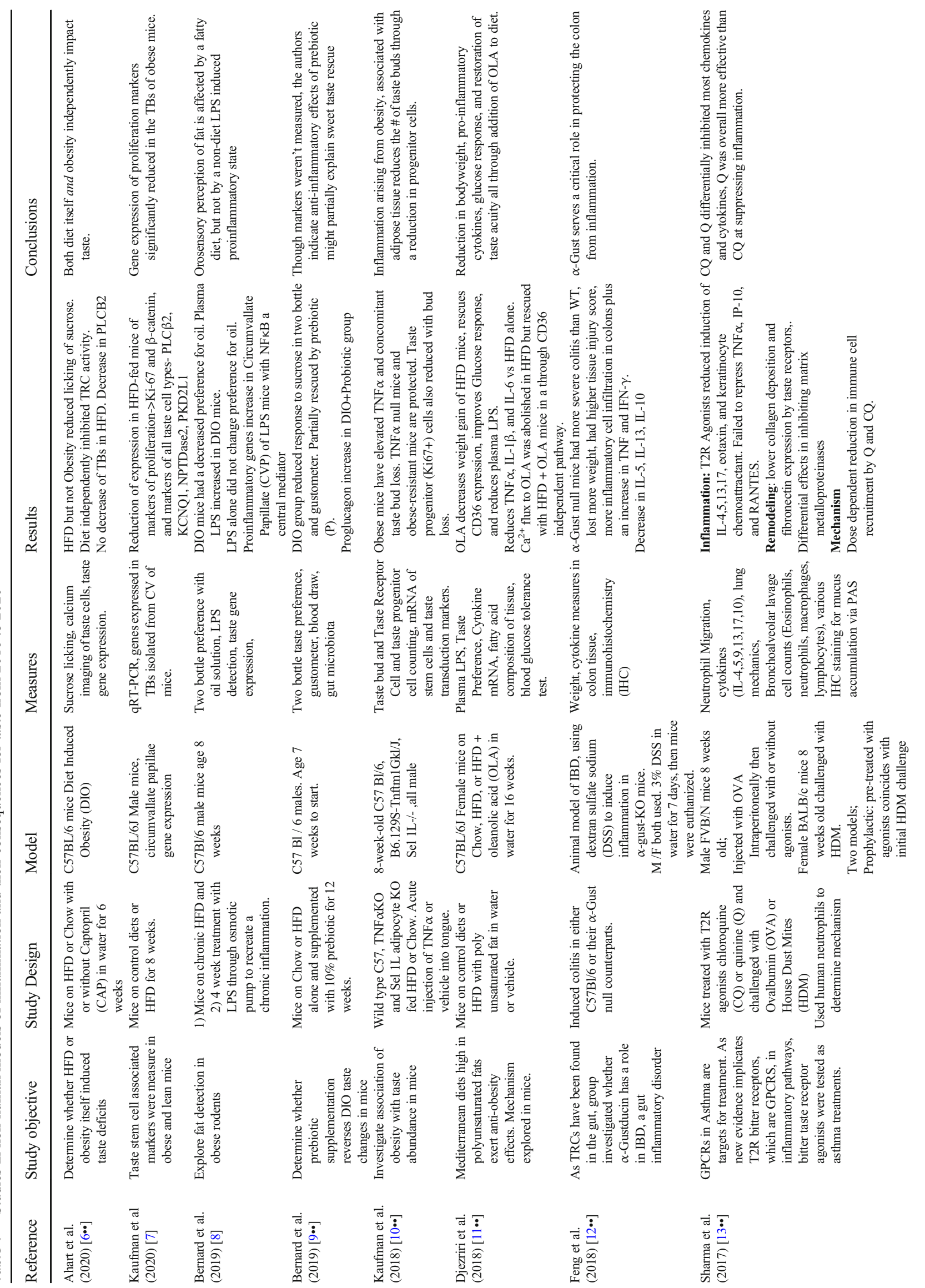




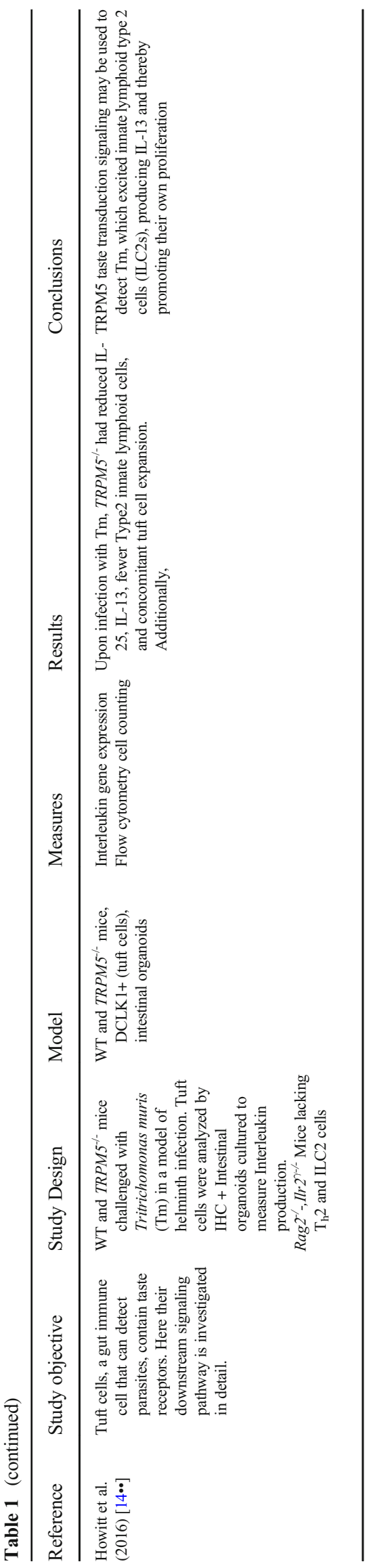

as an integral part of the sensory transduction pathway, without which taste sensations are altered.

A critical recent finding that will doubtlessly accelerate our understanding of the nexus between innate immunity and taste is that taste organoid cultures are also able to model an inflammatory response such as that in bacterial infiltration in vivo, with rapid induction of TNF and IL-6 observed in these in vitro cultures after stimulation with LPS [37]. These taste organoids also expressed many other classical markers of the immune response, including all members of the NF- $\mathrm{KB}$ pro-

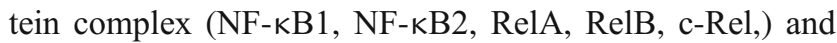
multiple Toll-like receptors, most markedly TLR2, 3, 4, and 5.

\section{The gastrointestinal tract}

Several autoimmune diseases are also linked to taste dysfunction, notably Sjögren's Syndrome (SS) [38], Inflammatory Bowel Disease (IBD) [39], and Systemic Lupus Erythematosus (SLE) in mice [40]. Each of these diseases impact taste signaling in their own way. For example, in SS, patients experience an infiltration of macrophages, plasma, and $\mathrm{T}$ cells into their lacrimal and salivary glands [41]. This leads to a reduction in salivary production, which itself reduces the ability to detect taste compounds, though not necessarily through a direct action on taste cells. In a mouse model of autoimmune disease with a phenotype akin to that of lupus or Sjögren's syndrome, taste buds were smaller, and fewer taste cells regenerated from taste stem cells in the native turnover process the a taste bud relies on to maintain fidelity [42]. In humans with IBD, taste sensitivity was generally blunted versus healthy controls, save for sour taste, which was elevated in IBD. Sour is thought to be transduced through Type III taste cells [43]; however, most of the receptors associated with the immune response that are reported to be present in the taste bud tend to be expressed in Type II cells [29, $44,45]$. In human colonic mucosa, the number of bitterreceptor (T2R38) expressing cells is higher in those who are obese than lean, and is confined to cells seeming to fit an enteroendocrine phenotype [46]. These cells would presumably be responsible for the chemical sensing of luminal contents, with their abundance strongly correlating with BMI in this sample. Interestingly, the stimulation of T2R108 receptors in enteroendocrine cells in the guts of diet-induced obese mice with a bitter extract from hops was linked to GLP-1 release, and an improvement in multiple metabolic measures including fat mass, glucose homeostasis and insulin sensitivity [47].

\section{Airway immunity}

When encountering microbes in the airway, the innate immune response must detect and respond to potentially harmful 
invaders, in a manner thought to be partially dependent on the T2R family of bitter receptors (for review see [44]). A recent report suggested that cells in the trachea expressing bitter taste receptors also expressed the tuft cell marker (a chemosensory cell located in the epithelium, linked to type 2 immunity through the taste-linked signaling channel TRPM5 (Transient receptor potential cation channel subfamily $\mathrm{M}$ member 5) [14••], DCLK1 (microtubule-linked protein kinase 1 ), comprising around $4 \%$ of epithelial cells [48]. When isolating mRNA from these cells, sequencing revealed RNA for multiple additional taste signaling elements, as well as for multiple cytokines implicated in the immune response.

Interestingly, many of the antibiotics commonly used to treat airway infections (including levofloxacin, tobramycin, and azithromycin) are also capable of activating the T2Rs (T2R1, T2R4, T2R14, and T2R20) present in the airway, validated in an in vitro FLAG tagged HEK cell system [49]. These receptors are expressed in smooth muscle cells within the airway walls, functioning in a manner that seems ancillary to the inflammatory response, to relax smooth muscles and aid in bronchodilation [50]. Using cultured human sinonasal epithelial cells, Lee et al. [51••] were able to demonstrate that solitary chemosensory cells in the airway express the same T1R2/T1R3 receptor heterodimers present in taste buds used for sweet taste detection. While amino acids have a range of tastes, some D-amino acids are able to activate the T1R2/T1R3 receptor, where in the mouth this would correlate to the eliciting of a sweet taste [52]. Lee et al. found that not only do bacterial isolates, for example Staphylococcus, from human airways produce several of such T1R-activating Damino acids (D-Leucine, D-Isoleucine, D-Phenylalanine), but also D-amino acids taken from these isolates were able to inhibit biofilm formation in a T1R-dependant manner.

\section{Cancer and its treatment}

Cancer, the inflammatory state association with it, and the treatment side-effects thereof are also all associated with changes in taste in humans $[53,54]$. In mice, the effects of cyclophosphamide, a common chemotherapeutic agent, are acutely damaging to taste cells, in particular type II and III cells [55]. This loss of taste cells seems to act through apoptosis, and be particularly damaging to the progenitor cells responsible for resupplying the taste bud. When fractionating doses of cyclophosphamide, a practice common in cancer treatment that can alleviate some of the more negative side effects commonly encountered, loss of taste was in fact prolonged, and more severe [56]. As taste loss can discourage eating, leading to broad negative outcomes, and further result in a significant reduction in quality of life, careful consideration should be made of the implications of these findings.
As cancer patients are at risk of cachexia (a wasting disorder characterized by severe extreme weight loss along with loss of muscle and body fat, and marked by a loss of appetite) and its associated morbidity and mortality, a recent study worked to untangle the attribution of each [15]. Counter to the hypothesis that treatment which damages rapidly dividing cells would impact taste cell renewal, the authors found no impact of chemotherapy on taste detection in hospitalized patients. They did find altered taste perception in both the chemotherapy and acute inflammatory group versus healthy controls; however, the marker CRP, and leukocyte counts did not correlate with dysfunction. This suggests that a broader inflammatory state may be affecting both populations. Care should be taken in interpreting these results as the study populations were, by the nature of the study, not standardized.

\section{Obesity, inflammation and taste}

While acute inflammation in the form of infection is well characterized, a chronic low-grade inflammation associated with obesity [57] is a remarkably widespread manifestation of long-term activation of the immune system. In obesity, white adipose tissue (WAT) is broadly remodeled, and is itself a source of cytokines [58], and a harbor for macrophages that promote systemic inflammation [59]. Further, pathologies associated with obesity such as atherosclerosis have an immune component themselves, with associated plaques composed of several types of immune cells, including macrophages and neutrophils [60]. Obesity is associated with lower levels of adiponectin, and higher levels of TNF $\alpha$ [61], IL-6, and CReactive Protein (CRP) [62]. IL-6 and CRP are associated with disease complications [63, 64], while TNF $\alpha$ is associated with insulin resistance and hyperleptinemia $[65,66]$. One recent study also implicated various signaling elements of taste (T1R2, T1R3, G $\alpha$-Gustducin, phospholipase C-beta 2, and TRPM5 channels) expressed in renal tissues in stimulation of the inflammasome, in a diabetic mouse model, where activation of the inflammasome could further be partially mediated by the sweet taste blocker lactisole [67].

A great deal of studies associate taste changes with obesity, with the preponderance of evidence supporting a reduction taste acuity [7, 68-70], although some work does show the opposite effect [71] or no change at all [72]. Recent work from our own group suggested a reduction in taste bud abundance in both mice [10••] and humans [7] with adiposity, alongside a reduction in expression of various taste-linked signaling elements in mice [7]. The latter result is paralleled in humans in work from Archer et al. [5••], where a pioneering RNA sequencing experiment examined differential expression patterns of obese and lean Caucasian women, from isolated fungiform taste papillae. In fact, 2 of the 3 ontological groupings of genes found to vary significantly between subjects were 


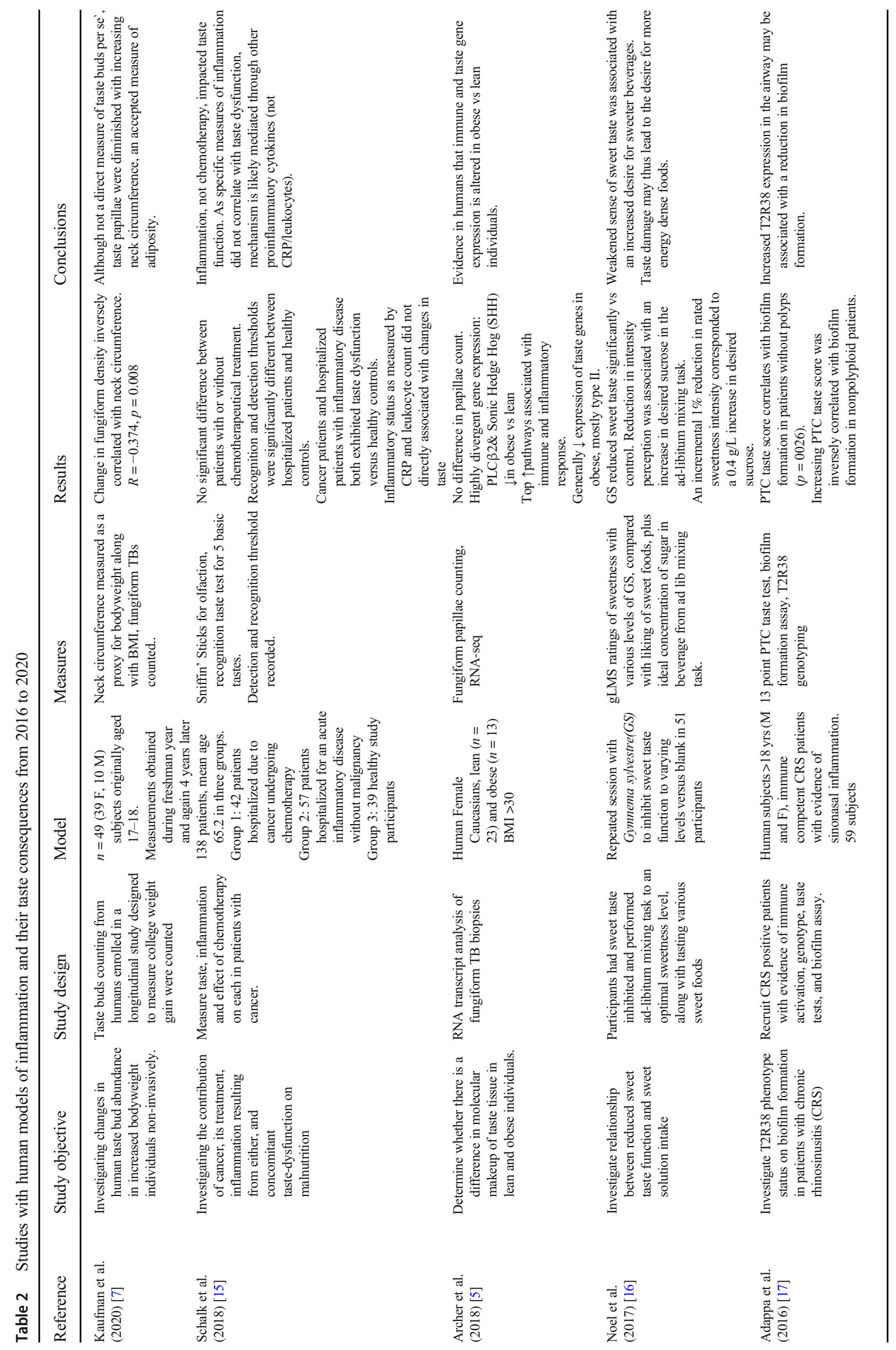


those associated with the immune response, and with sensory signaling.

Interestingly, in regions of the brain related to energy homeostasis (the hypothalamus and brainstem), both taste receptors (T1R3, T2R116) and taste signaling elements (G $\alpha 14$, TRPM5) are down-regulated by obesity in mice [73], in a manner which, we might speculate, seems itself homeostatic in nature. Although in an acute model of taste loss panelists tend to select foods of a higher sensory impact, and thus caloric content [16], a large genome-wide association study found limited evidence for an association between taste response and polymorphisms in taste genes, although GNAT3 alleles associated with greater sweet taste response were negatively associated with sugar intake in one sample [74]. Studies of patients undergoing bariatric surgery point toward rapid changes in taste after extreme weight loss [75-77], which may be inflammation-linked, as well as depending on the hormonal remodeling common in such interventions. Further work even implicates dampened CNS reward circuity linked to taste with an increase in obesity in adults [78, 79], which may differ from that seen in children [80].

Taste buds, or more specifically the population of specialized epithelial cells that make them up, are constantly renewed from a population of stem cells, which produce taste progenitor cells that further differentiate into 3 functionally and morphologically distinct taste cells [81], each cell type having a distinct half-life [82], or supporting keratinocytes. This complex and constant state of development requires a finely tuned balance of developmental and transcriptional regulators within the taste bud to ensure the judicious turnover of taste cells within the bud. The recent report by Archer [5••] showed a downregulation of genes expressed in the Type II taste cells responsible for sweet, bitter or umami detection in the fungiform papillae of obese versus lean women, as well as a reduction in expression of sonic hedge-hog $(\mathrm{SHH})$, a morphogen vital for taste cell development [83, 84]. Kaufman et al. showed a similar decrease in taste cell developmental markers in obese mice [7], with a concomitant increase in inflammatory markers and fewer taste buds in obese mice from an earlier work $[10 \bullet \bullet$.

\section{Conclusions and future work}

Taste perception in humans is sensitive to disease states, including obesity and acute infection. Circulating factors arising from our inflammatory state can also interact with taste cells themselves, their progenitor cells, innervating nerves, and with processing within the brain.

Recent work has made it clear that the taste system is plastic and responds to inflammatory insult, whether acute or chronic, and thus inflammation has a role in taste function and intake which cannot be discounted as we work toward behavioral approaches to treat metabolic diseases. Further, the identification of cells strikingly similar in phenotype to those we think of as taste cells throughout the body, which are seemingly fulfilling an immune sentinel role, highlights further links between immunity and taste. Future work should take advantage of the expanding array of molecular techniques available to study taste cells in vitro, and aim for longitudinal studies of taste and immunity pre- and post-obesity, to further elucidate the complex relationship between our perception of foods, and the consequences of over consumption.

\section{Declarations}

Conflict of interest authors do not have any potential conflicts of interest to disclose.

\section{References}

Papers of particular interest, published recently, have been highlighted as:

-• Of major importance

1. Boscolo-Rizzo P, Borsetto D, Fabbris C, et al. Evolution of altered sense of smell or taste in patients with mildly symptomatic COVID19. JAMA Otolaryngol - Head Neck Surg. 2020;146:1-5.

2. Cazzolla AP, Lovero R, Lo Muzio L, Testa NF, Schirinzi A, Palmieri G, et al. Taste and smell disorders in COVID-19 patients: role of interleukin-6. ACS Chem Neurosci. 2020;11:2774-81.

3.•- Parma V, Ohla K, Veldhuizen MG, et al. More than smell-COVID19 is associated with severe impairment of smell, taste, and chemesthesis. Chem Senses. 2020;45:609-22 Systematic examination of self-reported chemosensory defects in COVID-19.

4. Sukumaran SK, Lewandowski BC, Qin Y, Kotha R, Bachmanov AA, Margolskee RF. Whole transcriptome profiling of taste bud cells. Sci Rep. 2017;7:1-15.

5.• Archer N, Shaw J, Cochet-Broch M, Bunch R, Poelman A, Barendse $\mathrm{W}$, et al. Obesity is associated with altered gene expression in human tastebuds. Int J Obes. 2019;43:1475-84 To our knowledge this is the first study in human taste buds to show differential expression patterns in obese and lean subjects, in pathways related to inflammation and taste stem cell renewal and signaling.

6.• Ahart ZC, Martin LE, Kemp BR, Dutta Banik D, Roberts SGE, Torregrossa AM, et al. Differential effects of diet and weight on taste responses in diet-induced obese mice. Obesity. 2020;28:284 92 Experimental design to isolate taste-related effects of diet from those of weight gain in mice on high fat diet.

7. Kaufman A, Kim J, Noel C, Dando R. Taste loss with obesity in mice and men. Int J Obes. 2020;44:739-43.

8. Bernard A, Ancel D, Passilly-Degrace P, Landrier JF, Lagrost L, Besnard P. A chronic LPS-induced low-grade inflammation fails to reproduce in lean mice the impairment of preference for oily solution found in diet-induced obese mice. Biochimie. 2019;159:112-21.

9.• Bernard A, Ancel D, Neyrinck AM, Dastugue A, Bindels LB, Delzenne NM, et al. A preventive prebiotic supplementation improves the sweet taste perception in diet-induced obese mice. Nutrients. 2019. https://doi.org/10.3390/nu11030549 The first study using a dietary intervention specifically designed to alter the gut microbiome, aiming to reverse the effects of diet induced inflammation and 
concomitant taste dysfunction. Prebiotic rescued sweet taste preference in mice consuming a HFD.

10.• Kaufman A, Choo E, Koh A, Dando R. Inflammation arising from obesity reduces taste bud abundance and inhibits renewal. PLoS Biol. 2018;16:1-14 Obese mice have fewer taste buds, and increased inflammatory markers, which likely act on mechanisms of taste bud renewal. Inflammation or obesity resistant mice were protected from taste bud loss in obesity.

11.•D Djeziri FZ, Belarbi M, Murtaza B, Hichami A, Benammar C, Khan NA. Oleanolic acid improves diet-induced obesity by modulating fat preference and inflammation in mice. Biochimie. 2018;152: 110-20 This study showed a reduction of systemic inflammation by consumption of Oleanolic Acid and a subsequent increase for fat preference, giving support for dietary treatments reversing inflammation and obesity.

12.• Feng P, Chai J, Yi H, Redding K, Margolskee RF, Huang L, et al. Aggravated gut inflammation in mice lacking the taste signaling protein $\alpha$-gustducin. Brain Behav Immun. 2018;71:23-7 In a mouse model of IBD, mice lacking $\alpha$-gustucin had more severe inflammation according to several physical measures, and increases in proinflammatory cytokines.

13.• Sharma P, Yi R, Nayak AP, Wang N, Tang F, Knight MJ, et al. Bitter taste receptor agonists mitigate features of allergic asthma in mice. Sci Rep. 2017;7:1-14 Bitter receptor agonists used as treatments to alleviate inflammation and airway remodeling in mice.

14.• Howitt MR, Lavoie S, Michaud M, et al. Tuft cells, tastechemosensory cells, orchestrate parasite type 2 immunity in the gut. Science (80-). 2016;351:1329-33 A detailed study of the intestinal immune response in tuft cells to Helminths proceeding through chemosensory cells and their signaling elements, specifically TRPM5.

15. Schalk P, Kohl M, Herrmann HJ, Schwappacher R, Rimmele ME, Buettner A, et al. Influence of cancer and acute inflammatory disease on taste perception: a clinical pilot study. Support Care Cancer. 2018;26:843-51.

16. Noel CA, Sugrue M, Dando R. Participants with pharmacologically impaired taste function seek out more intense, higher calorie stimuli. Appetite. 2017;117:74-81.

17. Adappa ND, Truesdale CM, Workman AD, Doghramji L, Mansfield C, Kennedy DW, et al. Correlation of T2R38 taste phenotype and in vitro biofilm formation from nonpolypoid chronic rhinosinusitis patients. Int Forum Allergy Rhinol. 2016;6:783-91.

18. Medzhitov R. Origin and physiological roles of inflammation. Nature. 2008;454:428-35.

19. Sethi G, Sung B, Aggarwal BB. TNF: a master switch for inflammation to cancer. Front Biosci 2008;13(2):5094-107.

20. Tanaka T, Narazaki M, Kishimoto T. IL-6 in inflammation, immunity, and disease. Cold Spring Harbor perspectives in biology. 2014:6(10):a016295.

21. Marnell L, Mold C, Du Clos TW. C-reactive protein: ligands, receptors and role in inflammation. Clin Immunol. 2005;117:104-11.

22. Christ A, Latz E. The Western lifestyle has lasting effects on metaflammation. Nat Rev Immunol. 2019;19:267-8.

23. Gregor MF, Hotamisligil GS. Inflammatory mechanisms in obesity. Annu Rev Immunol. 2011;29:415-45.

24. Wang J, Obici S, Morgan K, Barzilai N, Feng Z, Rossetti L. Overfeeding rapidly induces leptin and insulin resistance. Diabetes. 2001;50:2786-91.

25. Hotamisligil GS, Erbay E. Nutrient sensing and inflammation in metabolic diseases. Nat Rev Immunol. 2008;8:923-34.

26. Myers MG, Cowley MA, Münzberg H. Mechanisms of leptin action and leptin resistance. Annu Rev Physiol. 2008;70:537-56.

27. Aguliar-Valles A, Kim J, Jung S, Woodside B, Luheshi GN. Role of brain transmigrating neutrophils in depression-like behavior during systemic infection. Mol Psychiatry. 2014;19:599-606.
28. Wang H, Zhou M, Brand J, Huang L. Inflammation activates the interferon signaling pathways in taste bud cells. J Neurosci. 2007;27:10703-13.

29. Feng P, Zhao H, Chai J, Huang L, Wang H. Expression and secretion of TNF-?? in mouse taste buds: a novel function of a specific subset of type II taste cells. PLoS One. 2012;7:e43140. https://doi. org/10.1371/journal.pone.0043140.

30. Wang H, Zhou M, Brand J, Huang L. Inflammation and taste disorders: mechanisms in taste buds. Ann N Y Acad Sci. 2009;1170: 596-603.

31. Feng P, Jyotaki M, Kim A, Chai J, Simon N, Zhou M, et al. Regulation of bitter taste responses by tumor necrosis factor. Brain Behav Immun. 2015;49:32-42.

32. Kumarhia D, He L, McCluskey LP. Inflammatory stimuli acutely modulate peripheral taste function. J Neurophysiol. 2016;115: 2964-75.

33. Cohn ZJ, Kim A, Huang L, Brand J, Wang H. Lipopolysaccharideinduced inflammation attenuates taste progenitor cell proliferation and shortens the life span of taste bud cells. BMC Neurosci. 2010;11:72.

34.• Pittman DW, Dong G, Brantly AM, He L, Nelson TS, Kogan S, et al. Behavioral and neurophysiological taste responses to sweet and salt are diminished in a model of subclinical intestinal inflammation. Sci Rep. 2020;10:1-13 In an acute model of intestinal inflammation using LPS in rats and mice, authors showed an attenuation of signal through the CT nerve and decreased licking behavior to sweet and salt stimuli, though there were species specific effects.

35. Zheng K, Lu P, Delpapa E, Bellve K, Deng R, Condon JC, et al. Bitter taste receptors as targets for tocolytics in preterm labor therapy. FASEB J. 2017;31:4037-52.

36. Camandola S, Mattson MP. Toll-like receptor 4 mediates fat, sugar, and umami taste preference and food intake and body weight regulation. Obesity. 2017;00:1-9.

37. Feng S, Achoute L, Margolskee RF, Jiang P, Wang H. Lipopolysaccharide-induced inflammatory cytokine expression in taste organoids. Chem Senses. 2020;45:187-94.

38. Gomez FE, Cassí-Nosthas L, Morales-de-León JC, Bourges H. Detection and recognition thresholds to the 4 basic tastes in Mexican patients with primary Sögren's syndrome. Eur J Clin Nutr. 2004;58:629-36.

39. Steinbach S, Reindl W, Dempfle A, Schuster A, Wolf P, Hundt W, et al. Smell and taste in inflammatory bowel disease. PLoS One. 2013;8:e73454. https://doi.org/10.1371/journal.pone.0073454.

40. Ballok DA, Szechtman H, Sakic B. Taste responsiveness and diet preference in autoimmune MRL mice. Behav Brain Res. 2003;140: 119-30.

41. Jonsson R, Bolstad AI, Brokstad KA, Brun JG. Sjögren's syndrome - a plethora of clinical and immunological phenotypes with a complex genetic background. Ann N Y Acad Sci. 2007;1108: 433-47.

42. Kim A, Feng P, Ohkuri T, Sauers D, Cohn ZJ, Chai J, et al. Defects in the peripheral taste structure and function in the MRL/lpr mouse model of autoimmune disease. PLoS One. 2012;7:e35588. https:// doi.org/10.1371/journal.pone.0035588.

43. Kataoka S, Yang R, Ishimaru Y, Matsunami H, Sévigny J, Kinnamon JC, et al. The candidate sour taste receptor, PKD2L1, is expressed by type III taste cells in the mouse. Chem Senses. 2008;33:243-54.

44. Carey RM, Lee RJ. Taste receptors in upper airway innate immunity. Nutrients. 2019;11:1-17.

45. Lee RJ, Cohen NA. Taste receptors in innate immunity. Cell Mol Life Sci. 2015;72:217-36.

46. Latorre R, Huynh J, Mazzoni M, Gupta A, Bonora E, Clavenzani P, et al. Expression of the bitter taste receptor, T2R38, in 
enteroendocrine cells of the colonic mucosa of overweight/obese vs. Lean subjects. PLoS One. 2016;11:1-16.

47. Kok BP, Galmozzi A, Littlejohn NK, Albert V, Godio C, Kim W, et al. Intestinal bitter taste receptor activation alters hormone secretion and imparts metabolic benefits. Mol Metab. 2018;16:76-87.

48. Liu S, Lu S, Xu R, Atzberger A, Günther S, Wettschureck N, et al. Members of bitter taste receptor cluster Tas2r143/Tas2r135/ Tas2r126 are expressed in the epithelium of murine airways and other non-gustatory tissues. Front Physiol. 2017;8:1-17.

49. Jaggupilli A, Singh N, De Jesus VC, Gounni MS, Dhanaraj P, Chelikani P. Chemosensory bitter taste receptors (T2Rs) are activated by multiple antibiotics. FASEB J. 2019;33:501-17.

50. Deshpande DA, Wang WCH, McIlmoyle EL, Robinett KS, Schillinger RM, An SS, et al. Bitter taste receptors on airway smooth muscle bronchodilate by localized calcium signaling and reverse obstruction. Nat Med. 2010;16:1299-304.

51.• Lee RJ, Hariri BM, McMahon DB, et al. Bacterial D-amino acids suppress sinonasal innate immunity through sweet taste receptors in solitary chemosensory cells. Sci Signal. 2017;10:1-12 Bacteria in the upper airway produce amino acids which trigger T1R2/3 in SCCs and result in a dampening of inflammation. This could be a mechanism by which some microbes create environments to outcompete others via alterations of host immunity. It also establishes the $\mathrm{T} 1 \mathrm{R} 2 / 3$ receptor as a pattern recognition receptor.

52. Bassoli A, Borgonovo G, Caremoli F, Mancuso G. The taste of Dand L-amino acids: in vitro binding assays with cloned human bitter (TAS2Rs) and sweet (TAS1R2/TAS1R3) receptors. Food Chem. 2014;150:27-33.

53. Spotten LE, Corish CA, Lorton CM, Ui Dhuibhir PM, O'Donoghue $\mathrm{NC}, \mathrm{O}$ 'Connor B, et al. Subjective and objective taste and smell changes in cancer. Ann Oncol Off J Eur Soc Med Oncol. 2017;28:969-84.

54. Murtaza B, Hichami A, Khan AS, Ghiringhelli F, Khan NA. Alteration in taste perception in cancer: causes and strategies of treatment. Front Physiol. 2017;8:1-10.

55. Mukherjee N, Pal Choudhuri S, Delay RJ, Delay ER. Cellular mechanisms of cyclophosphamide-induced taste loss in mice. PLoS One. 2017;12:1-23.

56. Delay ER, Socia SH, Girardin JL, Jewkes BC, King JH, Delay RJ. Cyclophosphamide and the taste system: effects of dose fractionation and amifostine on taste cell renewal. PLoS One. 2019;14:1-23.

57. Lumeng CN, Saltiel AR. Review series adipose tissue remodeling and obesity. J Clin Invest. 2011;121:2111-7.

58. Karastergiou K, Mohamed-Ali V. The autocrine and paracrine roles of adipokines. Mol Cell Endocrinol. 2010;318:69-78.

59. Strissel KJ, Stancheva Z, Miyoshi H, Perfield JW, DeFuria J, Jick $\mathrm{Z}$, et al. Adipocyte death, adipose tissue remodeling, and obesity complications. Diabetes. 2007;56:2910-8.

60. Legein B, Temmerman L, Biessen EAL, Lutgens E. Inflammation and immune system interactions in atherosclerosis. Cell Mol Life Sci. 2013;70:3847-69.

61. Hotamisligil GS, Atkinson RL, Spiegelman BM. alpha in human obesity and insulin resistance. Obesity and Insulin Resistance. 1995;95:2409-15.

62. Ellulu MS, Patimah I, Khaza'a H, Rahmat A, Abed Y, Sci AM. Obesity and inflammation: the linking mechanism and the complications. Arch Med Sci. 2017;13(4):851-63.

63. Den Hertog HM, Van Rossum JA, Van Der Worp HB, Van Gemert HMA, De Jonge R, Koudstaal PJ, et al. C-reactive protein in the very early phase of acute ischemic stroke: association with poor outcome and death. J Neurol. 2009;256:2003-8.

64. Danesh J, Kaptoge S, Mann AG, et al. Long-term interleukin-6 levels and subsequent risk of coronary heart disease: two new prospective studies and a systematic review. PLoS Med. 2008;5:0600-10.

65. Kirchgessner TG, Uysal KT, Wiesbrock SM, Marino MW, Hotamisligil GS. Tumor necrosis factor- $\alpha$ contributes to obesity- related hyperleptinemia by regulating leptin release from adipocytes. J Clin Invest. 1997;100:2777-82.

66. Uysal KT, Wiesbrock SM, Hotamisligil GS. Functional analysis of tumor necrosis factor (TNF) receptors in TNF- $\alpha$ - mediated insulin resistance in genetic obesity. Endocrinology. 1998;139:4832-8.

67. Zhou L, Huang W, Xu Y, Gao C, Zhang T, Guo M, et al. Sweet taste receptors mediated ROS-NLRP3 inflammasome signaling activation: Implications for diabetic nephropathy. J Diabetes Res. 2018;2018:1-15. https://doi.org/10.1155/2018/7078214.

68. Drewnowski A, Brunzell JD, Sande K, Iverius PH, Greenwood MRC. Sweet tooth reconsidered: taste responsiveness in human obesity. Physiol Behav. 1985;35:617-22.

69. Pepino MY, Finkbeiner S, Beauchamp GK, Mennella JA. Obese women have lower monosodium glutamate taste sensitivity and prefer higher concentrations than do normal-weight women. Obesity. 2009;18:959-65.

70. Fernandez-Garcia JC, Alcaide J, Santiago-Fernandez C, et al. An increase in visceral fat is associated with a decrease in the taste and olfactory capacity. PLoS One. 2017;12:1-14.

71. Hardikar S, Höchenberger R, Villringer A, Ohla K. Higher sensitivity to sweet and salty taste in obese compared to lean individuals. Appetite. 2017;111:158-65.

72. Frijters JE, Rasmussen-Conrad EL. Sensory discrimination, intensity perception, and affective judgment of sucrose-sweetness in the overweight. J Gen Psychol. 1982;107:233-47.

73. Chao DHM, Argmann C, Van Eijk M, et al. Impact of obesity on taste receptor expression in extra-oral tissues: emphasis on hypothalamus and brainstem. Sci Rep. 2016;6:1-14.

74. Hwang LD, Lin C, Gharahkhani P, Cuellar-Partida G, Ong JS, An $\mathrm{J}$, et al. New insight into human sweet taste: a genome-wide association study of the perception and intake of sweet substances. Am J Clin Nutr. 2019;109:1724-37.

75. Nielsen MS, Andersen INSK, Lange B, Ritz C, le Roux CW, Schmidt JB, et al. Bariatric surgery leads to short-term effects on sweet taste sensitivity and hedonic evaluation of fatty food stimuli. Obesity. 2019;27:1796-804.

76. Berthoud HR, Zheng H. Modulation of taste responsiveness and food preference by obesity and weight loss. Physiol Behav. 2012;107:527-32.

77. Burge JC, Schaumburg JZ, Choban PS, DiSilvestro RA, FlancbauM L. Changes in patients' taste acuity after Roux-en-Y gastric bypass for clinically severe obesity. J Am Diet Assoc. 1995;95:666-70.

78. Green E, Jacobson A, Haase L, Murphy C. Reduced nucleus accumbens and caudate nucleus activation to a pleasant taste is associated with obesity in older adults. Brain Res. 2011;1386:109-17.

79. Babbs RK, Sun X, Felsted J, Chouinard-Decorte F, Veldhuizen MG, Small DM. Decreased caudate response to milkshake is associated with higher body mass index and greater impulsivity. Physiol Behav. 2013;121:103-11.

80. Bohon C. Brain response to taste in overweight children: a pilot feasibility study. PLoS One. 2017;12:1-9.

81. Jones R. Taste bud regeneration and the search for taste progenitor cells. Bone. 2014;23:1-7.

82. Perea-Martinez I, Nagai T, Chaudhari N. Functional cell types in taste buds have distinct longevities. PLoS One. 2013;8:1-9.

83. Castillo-Azofeifa D, Losacco JT, Salcedo E, Golden EJ, Finger TE, Barlow LA. Sonic hedgehog from both nerves and epithelium is a key trophic factor for taste bud maintenance. Dev. 2017;144:3054-65.

84. Yang H, Cong WNA, Yoon JS, Egan JM. Vismodegib, an antagonist of hedgehog signaling, directly alters taste molecular signaling in taste buds. Cancer Med. 2015;4:245-52.

Publisher's Note Springer Nature remains neutral with regard to jurisdictional claims in published maps and institutional affiliations. 